\title{
OPEN BRIEF
}

\section{AAN \\ Ds. J. P. JOOSTE. \\ IN ANTWOORD OP DEN ZYNE VAN MEI 1871.}

\section{Mynheer!}

Uw brief ligt voor my. Ik zet my neder om hem te beantwoorden. Ik begin met den

\section{Afval van de Synode}

De oorzaak van dien afval is de gemeente. Tot getuigen roep ik op al de oude emigranten, die destyds de dryvers van die zaak waren. Ik zal hier enkelen by name noemen, als: Ph. Snyman, Ph. Schutte, Gerrit, Paul en Douw Kruger, G. Engelbregt, Th. Steyn, J. Kok, Wynand Smit, D. Jacobs, de familien van Wolmarans, Lombard en anderen. Ge kunt ook aan onzen Staatspresident vragen wat zyn overleden vader hem kort voor zyn dood op het hart heeft gedrukt, namelyk: "om wel toe te zien dat ik my niet onder de Kaapsche Synode moest verbinden".

Later, toen ik inzag, dat de scheiding van de Synode eene gewenschte zaak was, heb ik yverig daarvoor gewerkt. Nooit heb ik my echter tot dat einde van onwaarheden bediend, zoo als de kerkeraad van Lydenburg het doet voorkomen. Wat ik onder anderen van de Synode gezegd heb, dat zy onder den invloed van het Britsch gezag stond, en wat ik verklaard heb 
van een eed van getrouwheid aan het Britsch gezag, dien men wilde dat $\mathrm{ik}$ zou afleggen, dat is alles de waarheid. Tydens myne legitimatie aan de Kaap vroeg de Actuarius der Synode my om zoodanigen eed afteleggen. Op afraden echter van predikant Heins heb ik geweigerd.

Ik heb dus de mensche alhier nooit iets wys gemaakt met het doel om de afscheiding te bevorderen. En al uwe documenten die my van zoo iets en van nog vele andere dingen beschuldigen, zyn niets anders dan producten, in de pen gegeven door de hatelykste partydigheid tegen my. En wat betreft het doel der scheiding, dat was niets anders dan eene uitmuntende zorg om de vryheid en onafhankelykheid der emigranten te bewaren, maar niet, zooals gy herhaaldelyk beweert, het invoeren van het liberalisme. Aan sulk een gruwel werd destyds volstrekt niet gedacht.

Om hier over nu nog verder uit te weiden, gevoel ik geen lust. Ik walg al sinds lang van dien twist over de Synode en buitendien, of ge my aan dien afval schuldig of niet schuldig verklaart, dat is my net om het even; ik geef er niet zoo veel om als het zwart van myn nagel. Die onverschilligheid echter koester $\mathrm{ik}$ niet ten opzigte eener andere beschuldiging. Ik bedoel

\section{HET AFBREKEN DER GEREFORMEERDE KERK ALHIER.}

Die zaak trek ik my meer aan en begin terstond met de verklaring, dat ik die kerk niet afgebroken maar wel opgebouwd heb. Vóór myne komst alhier werd zy jammerlyk verwaarloosd. Toen de Emigranten zich hier gevestigd hadden, wilde de predikant Taylor, van Cradock, hen komen opzoeken. De Synode echter belette hem hier heen te gaan. Eindelyk gaf zy hem daartoe verlof, doch onder de uitdrukkelyke voorwaarde, dat hy geen kinderen zou doopen of annemen, dat hy zich alleen by zyn predikwerk moest bepalen en volstrekt geen sacramenten mogt uitdeelen. Later kwamen nu en dan enkele leeraars hen in vliegende haast bezoeken, met zeer veel lust om leeuwen en tygers, kameelen, olifanten en rhenosters, buffels en elanden te zien en zoo mogelyk een van die wonder-dieren te schieten, maar met zeer weinig lust om zich geheel en al aan de belangen des kerk toe te wyden. Niet een enkele had voor onze arme herderlooze kerk alhier zooveel over, dat hy zich aan haar als vast leeraar verbinden wilde. Hoe men hen ook bad en smeekte, ' $t$ was alles vruchteloos! Wel mooije en fraai klinkende beloften, maar geen hulp.

Toen ik reeds eenigen tyd hier was, beriep de gemeente van Rustenburg Ds. Andrew Murray, en zyn antwoord was, dat hy het beroep in zulk eene onbearbeide gemeente niet kon aannemen. Later bleek waarom hy dat niet kon. Hy had, over Worcester heen, de Kaapstad op het oog. En toen men uit de Kolonie geen leeraars krygen kon is onder myne leiding en medewerking gezorgd dat zy uit Holland zyn gekomen. Daarna, toen de kerk alhier reeds van een viertal leeraars voorzien was en toen hier meer en meer orde en veiligheid onder eene bestaanbare wet begon te heerschen en toen het pad gebaand en effen was, toen kwamen er vele uit de Kolonie en van elders zich hier indringen, en door die indringers, zoo als gy en uwe geestverwanten, is de kerk hier van een gescheurd en afgebroken. Antwoord toch nu hier niet op, dat myn kerk de Hervormde is 
en dat gy spreekt van de Gereformeerde. Als gy dat doet, moet ik u weer herinneren - al zoudt gy op nieuw van verontwaardiging gloeijen - dat myn kerk en de Gereformeerde een en dezelfde is.

Ik sprak daar van "een gloed van verontwaardiging" en doelde daarmede op hetgeen gy schryft bladzyde 6 en ik verlang dat gy nu vooral eens goed luisteren zult naar hetgeen $\mathrm{ik}$ hierover tot $\mathrm{u}$ te zeggen heb. Ik stel eerst weer een nieuw opschrift.

\section{OVER DEN GLOED VAN VERONTWAARDIGING DIE GEDURIG IN DE BORST VAN JOOSTE OPKLIMT.}

Verhit door dien gloed wordt gy nu een oproer-kraaijer en tracht gy op de fanatiekste wyze de gemeente tegen my op te hitsen. Ik zie $u$, in myne verbeelding, gloeijende van toorn en hoor $\mathbf{u}$ met donderende stem uitroepen: "grypt dien ketter en voert hem naar den brandstapel!" Niet waar, dat is de zin en de geest van uwe hartstochtelyke taal? ' $t$ Is niet de taal van een bezadigd gemoed, maar de taal van een zeloot, de taal van een fanatiek, die er niet om geeft, al wordt door zyn oproerschreeuwen wanorde, twist en tweedragt, haat en nyd en verbittering voortgebragt. En dat oproergeschreeuw heft gy aan op de nietigste gronden, op onwaarheden en valsche voorstellingen. Ik zal het $\mathrm{u}$ aantoonen. Gy beweert dat ik tegen de Kaapsch-Gereformeerde kerk ben, maar dat kunt gy my nooit bewyzen, want 't is onwaar. Ik heb nooit, noch met woorden noch met daden zoo iets getoond; in tegendeel, ik heb altyd getoond, met hart en ziel voor die kerk te zyn, en ik heb haar ook innig lief. Maar gy verwart hier alweer de kerk met de predikanten of liever met het kerkbestuur of synode. Die heb ik als zoodanig niet lief, daar kom ik voor uit. Hare handelwyze in vele opzigten stuit my geweldig tegen de borst. Gy beweert, dat ik de Synode met de zwartste kleuren afschilder, maar dat is weer onwaar; ik heb haar slechts afgeschilderd zooals zy was en als ik nu hare laatste handelingen aanschouw, dan zyn die kleuren nog niet zwart genoeg geweest. Gy beweert, dat ik de dochter wreedaardig van de moeder heb losgerukt, maar dat is weer een leugen. $\mathrm{Er}$ is hier geene wreedheid aan de dochter gepleegd; integendeel eene weldaad heb ik haar bewezen, want zy was meerderjarig en ik heb haar vry gemaakt en zy dankt er my nog steeds voor. Gy beweert, dat ik niet meer als predikant door de Kaapsche kerk erkend word, maar ik zeg u, dat die niet-erkenning van nul en geener waarde is, net precies als de schorsing van de predikanten Burgers en Kotze voor nul en van geener waarde verklaard zyn. Dit alles beweert gy zonder bewyzen en verhit door den gloed, die in uwe borst opklimt, doet gy het op de fanatiekste wyze, om de gemeente tegen my optehitsen.

Onder den invloed van die brandende hitte, die uwe borst verteert, schryft gy ook nog het een en ander over-de handelwyze van de Natalsche en Vrystaatsche Synoden, en daarop sal ik u nu dienen onder het opschrift:

De losse zandgronden van de Vrystaatsche en Natalsche Synoden.

De Synode van den Vrystaat weigert de broederlyke hand, die wy haar aanbieden, op de nietigste gronden. Vooreerst op onze verhouding waarin wy tegenover uwe kerk alhier staan, daarmede bedoelende, dat wy 
ons vyandelyk tegen over $\mathrm{u}$ hebben geplaatst. Maar gy weet toch wel beter, niet waar, want juist het tegenovergestelde heeft hier plaats gevonden. Gy en de uwen hebt eene vyandige houding tegenover ons aangenomen en zyt de eerste geweest om ons in allerlei soort van pamfletten en op andere meer bedekte wyzen aantevallen. $W_{y}$ daarentegen hebben $u$ van den beginne af aan de meeste goedwilligheid en toegenegenheid getoond. Of hebben wy den Predikstoel van Potchefstroom niet gesteld ter uwer beschikking? En hebben wy u niet te kennen gegeven dat gy van een beroep in een onzer vacante gemeenten kondt verzekerd zyn? En heeft men dan regt, vraag $\mathrm{ik}$, om onze verhouding tegenover u vyandig te noemen?

De andere grond waarop de Vrystaatsche Synode bouwt, om de aangebodene vereeniging afteslaan, is nog losser zandgrond, ja de ongerymdheid zelve. Zy zegt, dat myn schryven in der tyd te Wakkerstroom in stryd is met Art. 1 onzer kerkwetten. Dit noem ik de ongerymdheid zelve, want die kerkwet, waarop zy doelt, bestond toen nog niet, en zoo kon ik dan ook onmogelyk iets in stryd met die wet schryven.

Op de kansels van Natal, zegt gy, worden wy, ik en myne ambtgenooten, niet meer toegelaten. Indien dit waar is, ofschoon my daar van nog niets bekend is geworden, dan is de Natalsche Synode zeker door den zelfden onbroederlyken geest bestuurd geworden en heeft zy zeker op dezelfde losse gronden gebouwd, als de Synode van den Vrystaat. Doch genoeg hiervan.

lk vestig nu myn oog op hetgeen gy schryft van menig broeder van my, zitting nemende in de Kaapsche Synode en daarover wil ik nu met $u$ spreken onder het opschrift:

\section{De Liberalisten in de KaApsche Synode.}

Met die broeders van my in de Kaapsche Synode bedoelt gy zeker Liberalisten, mannen, die in uw oog vyanden van Christus, vyanden der waarheid zyn. Ik moet $\mathrm{u}$ echter ronduit bekennen dat $\mathrm{ik}$ zulke personen in de Synode niet ken. Maar, gy staat op een ander standpunt en ziet dus met een ander oog en zoo ziet gy pesten der christelyke kerk in uwe zoo hooggeroemde Synode. Hoe verschrikkelyk! Hoort dat, gy Synodaal gezinde mannen van Transvaal! In de Kaapsche Synode nemen, volgens Jooste, zitting, pesten der christelyke kerk en die in het oog van Jooste zoo magtige Synode is onmagtig om ze uit haar midden te verwyderen, gebonden als sy is aan handen en voeten onder het Britsch gezag. Zouden de Lydenburgers, dit lezende, ook nu nog volhouden, dat ik hen dat zoo maar heb wys gemaakt om hen van de Synode afvallig te maken? Ik geloof dat zy en alle eensdenkenden met hen nu wel wyzer zullen worden. Doch stappen wy hier van af en laat ons weer iets anders overwegen, namelyk eenige uwer wenschen en begeerten, onder het opschrift:

\section{Jooste Wenscht de Hervormde Kerk VAN DWALING te VerLossen en VAN DER HOFF TE BEKEEREN.}

Gy spreekt van uwe hartelyke begeerte om myne kerk terug te houden van de hand over hand toenemende dwaling en ik zeg $u$, dat daarvan niets in myne kerk te vinden is, en dat ge hier alweer de predikan- 
ten met de kerk verwart. Gy moest liever zeggen, dat wy predikanten op den dwaalweg zyn, dan zoudt gy duidelyker spreken, maar nu is uw geschryf op dat punt louter verwarring, Doch veronderstelt eens, gy hadt dwaling in onze kerk ontdekt, waarom wyst gy dan niet aan, waarin onze kerk toch dwaalt? En veronderstelt verder, wy zyn het die de kerk op den dwaalweg brengen, waarom komt gy niet tot ons en onderricht ons op broederlyke wyze, om ons alzoo van dien dwaalweg af te brengen? Maar dat durft gy zeker niet, omdat uw Stellenbossche geest daartoe zich niet bekwaam gevoelt. En wat betreft uwen wensch om my, zoo als gy zegt, te bekeeren tot de orthodoxie, daarop moet ik u antwoorden, dat gy zulk een wensch in uw hart niet koesteren kunt, om de eenvoudige reden, dat gy nog nooit eene poging hebt aangewend om dien wensch vervuld te zien. Als ik iets wensch, dan doe ik al wat ik kan, om dien wensch te bevredigen, maar gy niet; dus is het niets anders dan schynheiligheid, die u die woorden in de pen heeft gegeven en uwe verklaring van uw innig leedwezen en van geen de minste hoop te hebben op myne bekeering, is niets anders dan vroom gebeuzel, waarmede gy onnoozele zielen kunt om den tuin leiden, maar my niet. Maar dit daar gelaten, gy wilt my bekeeren tot de orthodoxie, niet waar? en roept op hoogen toon uit "ik ben orthodox!" Gy orthodox? Ja, gy beweert het, even als Ds. Andrew Murray in de Kaapstad, maar weet gy dan niet dat hy op de schaal van Ds. Kotze gewogen te ligt bevonden is? Ieder deskundige, die de strydschriften van die twee heeren, in den laatsten tyd over de predestinatie gevoerd, gelezen heeft, moet tot de conclusie komen: "Ds. Murray is van de leer der Vaderen afgeweken en is niet orthodox". Zoo zal het met u ook wel zyn. Gy maakt al eenige concessies op het punt van menschelyke woorden in den bybel voorkomende en dit juist is de eerste schrede om van het pad der orthodoxie aftedwalen. Doch hierover later. Gy zegt verder, dat gy myne aanmerking over den geest uit Stellenbosch met stilzwygen voorbygaat, maar ondertusschen weidt gy nog al in bloemryke taal uit in het raad geven en het afleggen eener verklaring van wat die Stellenbossche geest voornemens is te doen. En dit punt is wel waardig om er een nieuw Hoofdstuk mede te beginnen. Ik doe dat en stel tot opschrift:

De Stellenbossche geest rust zich uit om te Bevechten Den geest VAN DEN ANTICHRIST IN DE TRANSVAal.

$\mathrm{O}$, ik wenschte nu, dat ik de kunst van teekenen verstond! Ik teekende dan een bazuinblazer af naar de tronie van zekeren Stellenbosschen predikant en achter hem een verschrikkelyk heirleger in de gedaanten van springhanen, schorpioenen, hagedissen, kleine duiveltjies, enz., aangevoerd door al de Lucifers van Stellenbosch, gezeten op vale paarden en ongedresseerde ezels, ten stryde uitrukkende tegen de Transvaalsche ketters en dorstende naar hun bloed. Maar, daar ik niet teekenen kan, zal ik my maar met schryven vergenoegen.

De geest van Stellenbosch, zegt gy, zal te velde trekken tegen den geest van den Antichrist in de Z. A. Republiek.

Volgens $u$ is er dus zulk een geest en wel hier te lande. De geest van den Antichrist hier in de Transvaal!! Wat zullen de menschen hier bang 
worden als zy dat hooren. Doch daar ik volstrekt niet kan verdragen, dat gy myne menschen den schrik op het lyf jaagt, zal ik ze op dat punt inlichten, overtuigd zynde dat zy na de lezing daarvan, wel van dien schrik, dien gy hen wilt aanjagen, genezen zullen zyn. Myne inlichting op dat punt is als volgt:

De geest van den Antichrist bestaat slechts in de verhitte verbeelding van Jooste. $W_{y}$ toonen dat aan uit den bybel en de kerkgeschiedenis. Wie is, volgens den bybel de Antichrist? Is dat een bepaald persoon of is het eene rigting in de christelyke kerk? Ten allen tyd zyn er geweest, die meenden, dat er een bepaald persoon mede bedoeld werd. Er waren er in vroegere dagen, die keizer Nero, en in latere dagen, die keizer Napoleon en in den jongsten tyd, ten minsten hier in Transvaal, die koning Victoria met dien naam bestempelden. Doch dat is geheel en al verkeerd. Wy konden dit breedvoerig betoogen door al de schriftuurplaatsen uit de brieven van Johannes, die hier op betrekking hebben, aantehalen en te verklaren en bovendien ook nog eenige plaatsen uit de brieven van den kerkvader Ignatius, doch dan zouden wy te wydloopig moeten worden. Wy wyzen dus slechts op den 1sten brief van Johannes, kap. 2 vs. 18, waar melding gemaakt wordt van Antichristussen in 't meervoud en dat waren menschen, die in die dagen eene afgescheidene gemeente hadden opgerigt, later in de geschiedenis bekend onder den naam van Doceten. De leeraars dier gemeente beweerden dat Christus slechts een schynligchaam had gehad. Zy konden het zich waarschynlyk niet voorstellen, hoe Christus anders op de toppen der golven had kunnen wandelen, of hoe hy kon komen in de kamer by de apostelen, terwyl de deuren van dat vertrek gesloten waren, of, hoe hy met een waar menschelyk ligchaam ten hemel had kunnen varen. Waarschynlyk hadden zy, met Christus een schyn-ligchaam toetekennen, geen ander doel dan hunnen geliefden Meester te verheerlyken, in den waan verkeerende, dat een waar menschelyk ligchaam te onrein was voor den reinen menschenzoon, dien zy beschouwden als het afschynsel van Gods heerlykheid. Tegen die leeraars en hunne geestverwanten trekt Johannes te velde en noemt hen ook valsche profeten en verleiders en soms ook in't enkelvoud de Antichrist, zonder an eenig bepaald persoon te denken. Doch hoe dit ook zy, dit is zeker, dat de leer, die zy verkondigden, eene gevaarlyke kettery was. Het was eene rigting in de oude christelyke kerk, die den grondslag van het christendom dreigde te ondermynen. Want als Christus geen waarachtig mensch is geweest en hy slechts een schynligchaam heeft gehad, dan heeft hy ook slechts in schyn geleden en is slechts in schyn gestorven; dan vervalt de geheele verdienste van dat lyden en sterven; dan is zyne edelmoedige zelfopoffering van geen de minste waarde; dan is de lydensprediking onnut en de aanbeveling om zyn voorbeeld te volgen en zyne voetstappen te drukken ongerymd. $t^{\prime} I s$ om die reden dat Johannes zoo vurig tegen die ketters getreden heeft en wy verblyden er ons over dat hy zoo gedaan heeft, want daardoor is die dwaling langzamerhand te niet gegaan, ja zoo te niet gegaan, dat er thans in de gansche christenheid geene enkele secte meer bestaat, die de Anti-christelyke dwaling, waar tegen Johannes yvert, is toegedaan. Die kettery is al eenige honderde jaren geleden, uitgestorven en bygevolg zal de Stellenbossche geest, als hy te velde trekt tegen den 
geest van den Anti-christ, een vruchteloozen stryd beginnen en tegen niets anders vechten, dan tegen schimmen, die slechts spoken in de kranke hersenen van Jooste en zyne geestverwanten.

Ik ga voort met $u$ te spreken over wat gy noemt:

Het Liberalisme van van der Hoff en zYN stryd tegen Gods Woord.

Door stryd tegen Gods woord versta ik, wanneer men opzettelyk eenige uitdrukkingen of stellingen, in den bybel voorkomende, als leugenachtig ten toon stelt. En nu vraag ik $u$, hebt gy my dat aangetoond, hebt gy my dat bewezen? Neen, want gy weet niets anders in te brengen, dan dat ik in plaats van met Paulus te zeggen: "Geloof in den Heere Jezus" gezegd heb: "volgt Jezus' voorbeeld en drukt zyne voetstappen." En noemt gy dat stryd voeren met Gods woord, omdat ik niet letterlyk de bybelwoorden teruggeef, dan moet ik u zeggen, dat gy ook een bestryder zyt van Gods woord. Ik kom hier neer op uwe uitdrukking bl. 8 reg. 16, van onderen, waar gy zegt dat de zaligheid verbonden is aan het geloof in het eeuwig zoenbloed van Jezus. Ik daag u uit myn Heer, om ergens in den bybel zulk eene uitdrukking aan te wyzen.

En waarop grondt gy uwe beschuldiging van liberalisme? op die zelfde preek. En wat hebt gy als liberalisme in die preek ontdekt? Eenige, volgens uw oordeel, moderne uitdrukkingen en dan dat woord dat wy reeds in oogenschouw hebben genomen en dat reeds door my weerlegd is. Er blyven dus nog alleen over die moderne uitdrukkingen. En welke zyn die! Gy noemt er geen op. En waarom niet, omdat gy door die uitdrukkingen zeker niets bewyzen kunt. Daarom hebt gy ze maar zorgvuldig achterwege gehouden, goed inziende, dat gy, door daarop uwe beschuldiging te gronden, $\mathbf{u}$ slechts aan de bespotting van deskundigen zoudt hebben prys gegeven. Uwe geheele beschuldiging is dus niets anders dan hatelyke verdachtmaking, zonder eenige de minste bewysgronden. Groote woorden, holle klanken, anders niets.

En nu weer over iets anders:

\section{Het Colloguium Doctum.}

O schim van van der Lingen, rys op uit uw graf! Hoor wat een kweekeling van uw geliefd Stellenbosch Seminarie durft te beweren. Hy rangschikt $u$ onder de Liberalen. Hy durft te zeggen, dat alle liberalen tegen het colloquium zyn en dus zyt gy een van hen, want gy immers waart een van de sterkste tegenstanders van dat inquisitie-gerigt? Kom, sta aan myne zyde en verklaar aan Jooste dat hy zyne woorden moet terug trekken, of dat gy anders in uw graf niet rusten kunt.

Hiermede stappen wy van het colloquium af en gaan nu over tot een ander onderwerp, namelyk:

\section{Artikel 7 der Nederlandsche geloofsbelydenis.}

In bovenstaand Artikel wordt geleerd, dat Gods woord in den bybel vervat is. Iedereen, die de Hollandsche taal verstaat, denkt terstond by die uitdrukking aan een vat. En of nu al gedacht wordt aan een gouden, 
zilveren, koperen, yzeren, of aarden vat, doet niets ter zake. Al de hier genoemde stoffen zyn uit de aarde. I $\mathrm{k}$ ben dus in myn volle regt, als ik, overeenkomstig met bovengenoemde belydenis, den bybel noem een aarden vat. Het is de gereformeerde beschouwing van den bybel. Al de orthodoxe predikanten van Zuid-Afrika moeten hierin met my overeenkomen. Want Egeling schryft in zyn werk, getiteld: 'De weg der zaligheid;' "Niet alles wat in den bybel staat, is Gods woord" — en zie, dat werk van Egeling is door de boekvereeniging in de Kaapstad herdrukt en door de orthodoxe predikanten van de kolonie, Vrystaat en Natal, onder de gemeenten verspreid geworden. Al die orthodoxe heeren zyn dus met my van een en hetzelfde gevoelen en beschouwen den bybel uit hetzelfde standpunt als ik. Want als zy de gemeente, volgens Egeling, leeren: "niet alles wat in den bybel staat, is Gods woord." dan leeren zy daar mede hetzelfde wat ik gezegd heb: "de Bybel is volgens de Nederlandsche geloofsbelydenis een aarden vat." Ik ben dus, in dat opzigt, in zeer goed gezelschap.

Jezuitische valstrikken dOOR JoOste voOR VAN DER HOFF gespanNen.

Gy lokt my uit om meer openhartig nog voor myne gevoelens uit te komen en gy pryst en vleit my voor die openhartigheid. Hoe lief van $u$ ! Ik zal $\mathrm{u}$ hierop antwoorden, myn Heer Jooste, primo dat ik te oud ben om my door $\mathrm{u}$ te laten vangen en secundo, dat $\mathrm{ik} \mathbf{u}$ over vele dingen nog veel zou kunnen zeggen, maar gy kunt die nu nog niet dragen.

HET VOORNEMEN VAN VAN DER HOFF DAT HY JOOSTE NIET ZAL DAGVAARDEN VOOR DE BURGERLYKEN REGTER.

Gy hebt uw woord, onder den naam van Veritas gesproken, in dezen uwen open brief gewyzigd, verslapt en verwaterd en dit beschouw ik zoo goed als eene terugtrekking van uw vroeger gesproken woord, en dat is voor my nu satisfactie genoeg. Ik zal u dus niet dagvaarden.

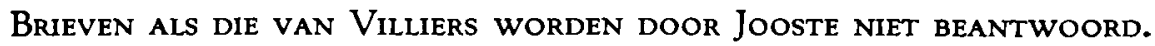

't Is waar, die brief was kras, maar gy hebt er aanleiding toe gegeven. Gy hebt dien man verbitterd door hem een zot te noemen en dat wel met verwyzing naar eene bybel plaats, die $u$ juist verbiedt om zoo iets te doen. Gy hebt $\mathrm{u}$ dus by het verbitteren van dien man nog schuldig gemaakt aan misbruik van bybel woorden. Als gy dat zoo ook van uwen kansel doet, dan kunt gy van den bybel net maken wat gy wilt en gy kunt hem alles laten zeggen. Is u zulke bybelverknoeijing in Stellenbosch geleerd? Arm Stellenbosch dan.

\section{De Dagen VAN Fredrik W EYER.}

Met het in herinnnering brengen van die dagen hebt gy ten doel om my aan de kaak te stellen als iemand die tegen vryheid van godsdienst in 't algemeen en in 't byzonder tegen de verkondiging van het evangelie van de 
kleurlingen is geweest. I $\mathrm{k}$ weet dat men my in der tyd den blaam heeft opgelegd dat $\mathrm{ik}$ Weyer belet heb om voor de kleurlingen godsdienst te houden, doch dit is leugentaal. Ik verlangde slechts van hem, om even als zulks in de Kaap kolonie de gewoonte was, dat hy voor den kerkeraad een examen zou afleggen, doch dat wilde hy niet doen en zette zyn werk naar eigen goeddunken voort. Daarop heeft de Landdrost alhier, geheel tegen myn zin in, hem dat oefening houden belet. Ziedaar alles. En hierby verzeker $\mathrm{ik}$ u dat $\mathrm{ik}$ een warme voorstander ben van vryheid van godsdienst, meer welligt dan gy en uwe geestverwante.

\section{JOOSTE IS OP WEG OM LIBERAAL TE WORDEN.}

Gy zegt ook al dat er in den bybel woorden voorkomen, die door private menschen gesproken zyn en dat het onderlinge gesprek van Philippus en Nathanael geen woorden Gods zyn, ja zelfs ook dat er Duivels woorden in voorkomen. Wees op uwe hoede, mynheer Jooste, want als gy zoo blyft voortgaan zult gy in den bybel eene tallooze menigte van dergelyke woorden vinden en ten langen leste, zullen er, zoo doende, niet vele woorden Gods over blyven. Of zyn niet de meeste Psalmen woorden en ontboezemingen van vrome menschen tot God? $\mathrm{O}$, wee $u$, gy staat reeds op een hellende vlakte, die $u$ vroeg of laat naar den afgrond van het liberalisme zal heen slepen!

Uwe beleedigende taal, die gy voert tegen de gansche gemeente van de Transvaal, alsof zy de onnoozelste en domste menschen waren, die zich zoo makkelyk en zoo spoedig door my om den tuin lieten leiden en die slechts met eenige vooroordeelen tegen het Britsch gezag bezield waren, alsmede uw zorgvuldig schuil houden om my onder myne preek in de kerk te komen beluisteren, en nog eenige andere dingen, ga ik met verachtend stilzwygen voorby en eindig met de versekering, dat ik voortaan in 't geheel van uw geskryf tegen my geen notitie meer zal nemen.

Potchefstroom, Junie 1871.

D. VAN DER HOFF. 